\title{
Intraoperative intravitreal triamcinolone decreases macular edema after vitrectomy with phacoemulsification
}

This article was published in the following Dove Press journal:

Clinical Ophthalmology

16 August 2012

Number of times this article has been viewed

\author{
D Wilkin Parke III \\ Robert A Sisk \\ Timothy G Murray \\ Department of Ophthalmology, \\ Bascom Palmer Eye Institute, \\ University of Miami, Miller School of \\ Medicine, Miami, FL, USA
}

Background: The purpose of this study was to evaluate the incidence and amount of macular edema by optical coherence tomography (OCT) after combined small gauge sutureless vitrectomy with phacoemulsification and intravitreal triamcinolone.

Methods: This retrospective case series included 194 consecutive eyes undergoing nonemergent vitrectomy with phacoemulsification and intravitreal triamcinolone. Ninety-one eyes had preoperative and postoperative OCT available and were included in the analysis. The eyes were evaluated for retinal thickness with preoperative and postoperative OCT, and for preoperative and postoperative best-corrected visual acuity. The main outcome measures were retinal thickness, OCT appearance, and best-corrected visual acuity.

Results: The incidence of macular edema in all eyes preoperatively was $64.8 \%$ and postoperatively was $50.5 \%$. Mean central subfield and center point thickness in eyes with macular edema preoperatively were $361 \mu \mathrm{m}$ and $349 \mu \mathrm{m}$, respectively, and postoperatively were $315 \mu \mathrm{m}$ and $304 \mu \mathrm{m}$, respectively. In eyes without preoperative macular edema, mean preoperative central subfield and center point thickness were, respectively, $210 \mu \mathrm{m}$ and $181 \mu \mathrm{m}$ versus $220 \mu \mathrm{m}$ and $192 \mu \mathrm{m}$ postoperatively. Best corrected visual acuity improved from 20/190 preoperatively to 20/150 at postoperative month 1 and 20/110 at month 6. Postoperative intraocular pressure $\geq 25 \mathrm{mmHg}$ was observed in $7.7 \%$ of eyes, none of which required surgical intervention for steroid-induced glaucoma.

Conclusion: Use of intravitreal triamcinolone with combined vitrectomy and phacoemulsification may play an important role in modulating postoperative macular edema. Adverse pressure rise is infrequent and usually limited.

Keywords: triamcinolone, macular edema, vitrectomy, corticosteroids

\section{Introduction}

Macular edema is a common source of visual limitation in post-vitrectomy eyes as well as those that have undergone phacoemulsification cataract extraction. While the incidence of macular edema after phacoemulsification has been relatively well characterized, that of macular edema after vitrectomy has limited data, particularly involving optical coherence tomography (OCT). OCT is now widely used for the diagnosis and analysis of macular edema over time, offering quantitative and qualitative data that are highly reproducible. Prior to OCT, Staudt et al and McDonald et al found evidence of leakage on postoperative angiography in $80 \%$ of macular hole surgeries and $70 \%$ of epiretinal membrane studies. ${ }^{1,2}$ More recently, Kim et al incorporated OCT into an investigation of post-vitrectomy macular edema. The study reported that $47 \%$ of eyes undergoing vitrectomy for epiretinal
Correspondence: Timothy G Murray Bascom Palmer Eye Institute, 900 NW I7th Street, Miami, FL 33I36, USA

Tel +I 3053266000

$\mathrm{Fax}+\mathrm{I} 3053266417$

Email tmurray@med.miami.edu 
membrane, macular hole, or vitreous hemorrhage had evidence of macular edema on postoperative OCT. ${ }^{3}$

Combination of vitrectomy with phacoemulsification is performed commonly as a means to facilitate intraoperative and postoperative view to the posterior segment, and to avoid the risks and costs inherent in a second phacoemulsification surgery to a vitrectomized eye. Several recent series have shown comparative improvement in postoperative visual acuity when vitrectomy is combined with phacoemulsification, with no associated rise in frequency of complications. ${ }^{4-9}$

Vitrectomy and phacoemulsification individually, as well as the combination of both surgeries, have been shown to induce macular edema that can negatively affect visual recovery. There has been considerable interest in medications adjuvant to surgery to address this problem. Intravitreal agents, particularly anti-inflammatory agents such as intravitreal triamcinolone acetonide, have attracted recent interest in this respect. ${ }^{10-14}$

This retrospective, consecutive case series presents a preoperative and postoperative OCT analysis of eyes that underwent combined phacoemulsification and vitrectomy with intravitreal triamcinolone acetonide. The primary objective was to analyze the incidence and alteration in macular edema after surgery.

\section{Materials and methods}

The study was performed with the approval of the University of Miami institutional review board and in accordance with the US Health Insurance Portability and Accountability Act and Declaration of Helsinki guidelines. A retrospective review was conducted of all patients who underwent combined sutureless 23 gauge pars plana vitrectomy with phacoemulsification cataract extraction and intravitreal triamcinolone acetonide between January 1, 2006 and March 1, 2009 at the Bascom Palmer Eye Institute by a single vitreoretinal and ocular oncology surgeon (TGM) and his surgical colleagues. All patients with less than 6 months of follow-up were excluded. All patients had a clinically significant cataract at the time of surgery. Surgery was performed using the Accurus 2500 surgical system (Alcon Laboratories, Fort Worth, TX). Preoperative intraocular lens biometry was performed using the IOL Master (Carl Zeiss Meditech, Dublin, CA). Postoperative clinic evaluations were performed at one day, one week, one month, 3 months, 6 months, and 12 months. Refractions were performed at one or 3 months postoperatively. All patients received topical anti-inflammatory and antibiotic drops postoperatively.
All patients gave their informed consent for surgery, and received regional or general anesthesia and standard Betadine ${ }^{\circledR}$ preparation. After sterile draping, 23-gauge trocars were inserted in a beveled fashion $3.5 \mathrm{~mm}$ posterior to the limbus. The infusion was clamped and the superior ports occluded while phacoemulsification with clear corneal wounds was performed. After nucleus and cortex removal, a three-piece acrylic MA60AC or MA50BM intraocular lens (Acrysof ${ }^{\circledR}$, Alcon) was folded and inserted through an enlarged corneal wound into the capsular bag or alternatively the ciliary sulcus in the setting of capsular compromise. The corneal wound was sutured before vitrectomy. A 130 degree wide field viewing system (Advanced Visual Instruments Inc, New York, NY) was used. Vitrectomy with lifting of posterior hyaloid was performed in all cases. Membrane peel, internal tamponade, endolaser, and encircling bands were variably used. After all cannulae were removed, $4 \mathrm{mg}$ of triamcinolone acetonide (Triesence ${ }^{\circledR}$, Alcon Laboratories) was injected through the pars plana into the vitreous cavity with a 27 gauge needle. Subconjunctival gentamicin $20 \mathrm{mg}$ and dexamethasone $4 \mathrm{mg}$ were injected at the conclusion of the procedure.

Study characteristics recorded included age, gender, presence of diabetes, primary surgical indication, past ocular history, lens status, previous intraocular surgery, laser, and intravitreal injections. Preoperative and postoperative visual acuity and intraocular pressure, intraoperative and postoperative complications, and postoperative interventions were recorded.

Preoperative and postoperative OCT was performed with the Stratus OCT3 machine (Zeiss-Humphrey Systems, Dublin, CA). Some of the patients underwent spectral domain OCT as well, but for consistency of interpretation, only the time-domain Stratus images were used in this study. OCT was performed by a trained technician who was a member of a dedicated photography department. Center point thickness and central subfield thickness were measured in microns. Values were obtained from the macular thickness map and data table, and the scans were evaluated retrospectively for artifact, decentration, or media irregularity preventing any significant signal uptake. Presence of other causes of retinal thickening, such as tumors, fibrosis, or hemorrhage that precluded accurate quantitative measurement or qualitative assessment of macular edema excluded that eye from the study. Macular edema was quantitatively defined as a central subfield $\geq 272 \mu \mathrm{m}$, a value reported by Chan et al as three standard deviations above the mean thickness of $212 \mu \mathrm{m}$ and used previously with Stratus OCT3 characterization 
of macular edema. ${ }^{15,16}$ This value of $272 \mu \mathrm{m}$ was similarly employed by Kim et al to define macular edema on OCT after vitrectomy. ${ }^{3}$ The quantitative threshold was used in combination with retrospective OCT image interpretation by two reviewers (DWP and TGM) to confirm that the appearance was consistent with macular edema and not other anatomic distortion, like foveal tumor or fibrosis.

\section{Statistical analysis}

Numerical OCT, intraocular pressure, and logMAR values were compared using the paired Student's $t$-test. Snellen visual acuities were changed to $\log$ MAR format for analysis. Statistical calculations were performed using Microsoft Excel 2010 software. The following convention was used for acuities too poor for a Snellen value: count fingers 20/2000, hand motion 20/20,000, and light perception 20/200,000.

\section{Results}

Table 1 lists the baseline characteristics for the cohort. A total of 194 eyes from 185 patients underwent combined 23 gauge sutureless vitrectomy with phacoemulsification and intravitreal triamcinolone acetonide during the study period for various indications. Of those eyes, 103 were excluded for not having a preoperative OCT or a postoperative OCT within 90 days of surgery, or for the presence of a foveal lesion that precluded accurate evaluation of the presence or amount of ME. Sixty of the 103 excluded eyes did not have a preoperative or postoperative OCT, and 43 were excluded due to a foveal lesion. The remaining 91 eyes in 95 patients were included in the primary analysis.

Mean patient age at surgery was 61.1 years, and mean follow-up was 356 (range 184-645) days. Two eyes had previously undergone vitrectomy. All eyes were phakic prior to surgery and had clinically significant cataractous lens change. Three eyes were from diabetic patients. The primary indication for surgery was refractory cystoid macular edema without radiation exposure in 11 , radiation retinopathy with

Table I Baseline characteristics

\begin{tabular}{ll}
\hline Study eyes $(\mathrm{n})$ & $9 \mathrm{I}$ \\
Mean age in years (range) & $6 \mathrm{I.I}(29.8-88.9)$ \\
Male (\%) & $42(46 \%)$ \\
Mean follow-up in days (range) & $356(184-645)$ \\
History of prior vitrectomy (\%) & $2(2.2)$ \\
OCT mean days before surgery (range) & $17(\mathrm{I}-54)$ \\
OCT mean days after surgery (range) & $36(15-76)$ \\
Eyes with preoperative macular edema (\%) & $59(64.8 \%)$ \\
Mean preoperative intraocular pressure (range) & $16.1(10-52)$ \\
\hline
\end{tabular}

Abbreviation: OCT, optical coherence tomography. refractory cystoid macular edema in 33, epiretinal membrane in 11, vitreous hemorrhage in two, coloboma in two, dislocated lens in one, macular schisis in two, retinal detachment in nine, retinal and choroidal vascular tumors in nine, exudative macular degeneration in five, primary intraocular lymphoma in two, Coats' disease in three, and uveal effusion syndrome in one (see Table 2). Twelve eyes had noted optic nerve compromise with afferent pupillary defect from prior radiation optic neuropathy. Surgery included membrane peeling in 30 , endolaser in 45 , fluid-air exchange and gas tamponade in four, iris retractors in three, and silicone oil removal in two. Fifty-three required additional intravitreal injections after surgery (32 for cystoid macular edema, seven for wet age-related macular degeneration, eight for radiation retinopathy, two for diabetic macular edema, two for neovascular glaucoma, and two for choroidal neovascular membranes secondary to angioma). YAG capsulotomy for posterior capsular opacification was performed in 11 eyes.

OCT was performed on average 17 days prior to surgery (range 1-54 days), and 36 days post-surgery (range 15-76 days). Across all 91 eyes, the mean preoperative central subfield thickness was $279 \mu \mathrm{m}$ and mean center point thickness was $261 \mu \mathrm{m}$. Macular edema, as defined by a central subfield thickness $>272 \mu \mathrm{m}$ with qualitative evidence of macular edema on review of OCT images, occurred in 59 of 91 eyes $(64.8 \%)$ preoperatively. The mean central subfield thickness in eyes with preoperative macular edema was 361 (range 277-568) $\mu \mathrm{m}$, and center point thickness was 349 (range 166-596) $\mu \mathrm{m}$. The mean thickness in eyes without preoperative macular edema was 210 (range 165-257) $\mu \mathrm{m}$, and center point thickness was 181 (range 145-236) $\mu \mathrm{m}$.

In all eyes, postoperative central subfield was $270 \mu \mathrm{m}$ (mean change $-8.7 \mu \mathrm{m}$ ) and postoperative center point

Table 2 Indications for surgery

\begin{tabular}{ll}
\hline Indication for vitrectomy & $\mathrm{n}(\%)$ \\
CME with radiation retinopathy & $33(36.3)$ \\
CME without radiation exposure & $\mathrm{II}(\mathrm{I} 2 . \mathrm{I})$ \\
Epiretinal membrane & $\mathrm{II}(\mathrm{I} 2 . \mathrm{I})$ \\
Retinal detachment & $9(9.9)$ \\
Vascular tumor & $9(9.9)$ \\
Exudative macular degeneration & $5(5.5)$ \\
Coats' disease & $3(3.3)$ \\
Primary intraocular lymphoma & $2(2.2)$ \\
Vitreous hemorrhage & $2(2.2)$ \\
Coloboma & $2(2.2)$ \\
Macular schisis & $2(2.2)$ \\
Dislocated crystalline lens & $\mathrm{I}(\mathrm{I} .1)$ \\
Uveal effusion syndrome & $\mathrm{I}(\mathrm{I} .1)$ \\
\hline
\end{tabular}

Abbreviation: CME, cystoid macular edema. 
thickness was 252 (mean change $-9.4 \mu \mathrm{m}$ ). Eyes with preoperative macular edema were analyzed separately from eyes without preoperative macular edema, because the desired effect of intravitreal triamcinolone acetonide in those two groups differed. Improvement of macular edema was of interest in the first group, whereas maintenance of normal retinal thickness and avoidance of macular edema was of interest in the second.

Fifty-nine eyes $(64.8 \%)$ had macular edema preoperatively, and in these eyes, postoperative central subfield and center point thickness were $315 \mu \mathrm{m}$ and $304 \mu \mathrm{m}$, respectively (with ranges of 187-469 $\mu \mathrm{m}$ and 170-503 $\mu \mathrm{m}$, see Figure 1). The change from preoperative thickness was $-46.9 \mu \mathrm{m}$ for central subfield (range -311 to $+140 \mu \mathrm{m}, P=0.025$ ) and $-46.0 \mu \mathrm{m}$ for center point thickness (range -346 to $+167 \mu \mathrm{m}$, $P=0.062)$. Fifteen of 59 eyes $(25.4 \%)$ with preoperative macular edema had resolution of macular edema on postoperative OCT.

Thirty-two eyes $(35.2 \%)$ did not have preoperative macular edema. Their postoperative central subfield and center point thickness were 220 (range 136-404) $\mu \mathrm{m}$ and 192 (range 110-441) $\mu \mathrm{m}$ (see Figure 2). The change from preoperative OCT thickness for central subfield was +10.6 (range -181 to +286$) \mu \mathrm{m}(P=0.052)$ and for center point thickness was +11.1 (range -145 to +269$) \mu \mathrm{m}(P=0.061)$. Two of 32 eyes $(6.3 \%)$ without preoperative macular edema developed postoperative macular edema.

Mean best-corrected visual acuity was 20/190 (logMar 0.98 , range $20 / 40$ to LP) at preoperative baseline. Mean best-corrected visual acuity one week after surgery was
20/215 ( $\log$ MAR 1.03, range 20/20 to LP). At month 1 , best-corrected visual acuity was $20 / 150(\log$ MAR 0.87 , range 20/20 to LP); at month 3, it was 20/125 (logMAR 0.80, range 20/20 to LP); and at month 6, it was 20/110 ( $\log$ MAR 0.73, range $20 / 20$ to LP). A statistically significant change in vision from baseline was noted at month $6(P=0.043)$.

In eyes with preoperative macular edema, the preoperative best-corrected visual acuity was 20/150 (logMAR 0.88) and at postoperative month 6 was 20/95 (logMAR 0.67). In eyes without preoperative macular edema, the preoperative best-corrected visual acuity was 20/255 ( $\log$ MAR 1.11 ) and at postoperative month 6 was 20/130 (logMAR 0.81). There was no statistically significant change in vision in either group.

Intraocular pressure was measured preoperatively and at each postoperative visit. The mean preoperative intraocular pressure was 16.1 (range 10-52) $\mathrm{mmHg}$. Intraocular pressure at postoperative month 1 was 15.6 (range 8-45) $\mathrm{mmHg}$, at month 3 was 14.8 (range 9-34) $\mathrm{mmHg}$, and at month 6 was 14.4 (range 9-28) mmHg. Four eyes (4.4\%) had a preoperative intraocular pressure $\geq 25 \mathrm{mmHg}$. Seven eyes $(7.7 \%)$ had at least one postoperative intraocular pressure $\geq 25 \mathrm{mmHg}$, excluding postoperative day 1 . Postoperative day 1 intraocular pressure was excluded from analysis because intraocular pressure at that time was much more likely due to surgical procedure, tamponade, or retained viscoelastic than to the pharmacologic effect of intravitreal triamcinolone acetonide. Of the seven eyes with an elevated intraocular pressure value postoperatively, four were placed on topical intraocular pressure-lowering medication, with normalization of the

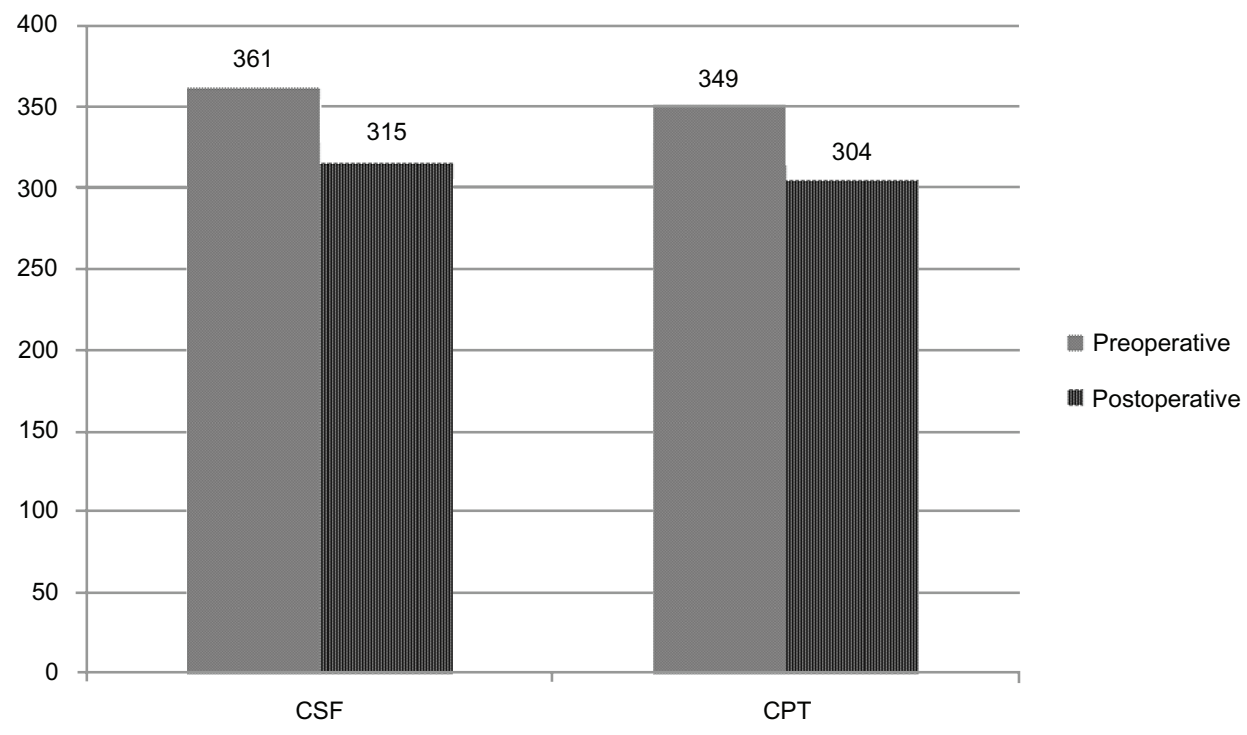

Figure I Preoperative and postoperative CSF and CPT $(\mu \mathrm{m})$ in eyes with preoperative macular edema. Abbreviations: CSF, central subfield thickness; CPT, central point thickness. 


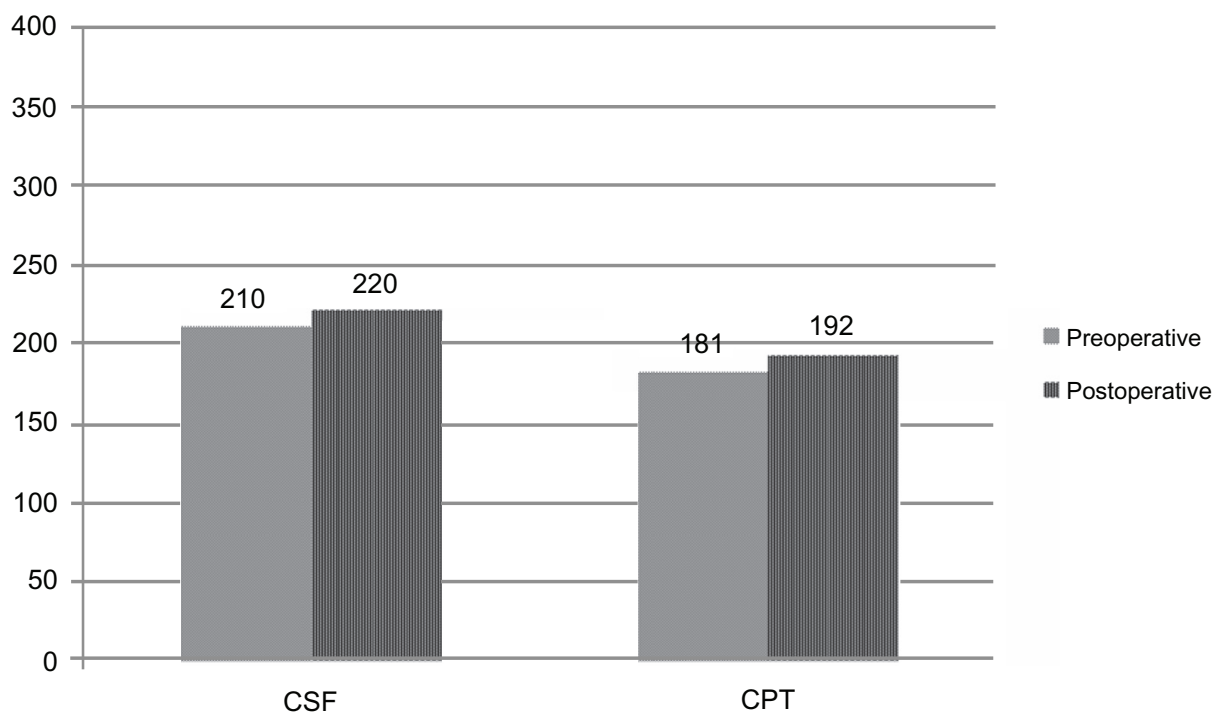

Figure 2 Preoperative and postoperative CSF and CPT $(\mu \mathrm{m})$ in eyes without preoperative macular edema. Abbreviations: CSF, central subfield thickness; CPT, central point thickness.

intraocular pressure; two were observed and normalized after a single visit in which the intraocular pressure was in the range of $25-29 \mathrm{mmHg}$, and one eye developed a chronic synechial angle closure due to neovascularization and eventually underwent Baerveldt glaucoma drainage implant surgery 6 weeks postoperatively.

\section{Discussion}

Much less is known about the incidence of macular edema after vitrectomy than after phacoemulsification and intraocular lens placement. Macular edema as a consequence of vitrectomy has probably been under-recognized for a variety of reasons, including frequent coexistence of other macular pathology that creates or contributes to macular edema, and difficulty with macular examination in the setting of significant vitreoretinal pathology or gas or oil tamponade. Angiography was not done routinely in these patients to seek out postoperative macular edema. The advent of OCT allows more precise, reliable, and noninvasive observation of even mild macular edema. OCT has already proven its clinical value in the detection and monitoring of pseudophakic macular edema and myriad vitreoretinal disorders. Now it is also enabling better characterization of post-vitrectomy macular edema. ${ }^{3,14}$

Macular edema is a complex manifestation of several different pathogenic processes. Triamcinolone probably modulates macular edema by a variety of mechanisms. Inhibition or downregulation of inflammatory mediators, preservation of capillary integrity and consequently that of the blood-retinal barrier, neuroprotection, and anti-vascular endothelial growth factor activity have all been implicated as important effects of triamcinolone. ${ }^{17-21}$

In the study by Kim et al, macular edema occurred in $47 \%$ of eyes by OCT after vitrectomy alone, the majority of which were done for macular pathology. Reports of macular edema after combined phacoemulsification with vitrectomy are in the $8 \%-9 \%$ range. ${ }^{22,23}$ Combination of phacoemulsification, intraocular lens placement, and vitrectomy probably creates more inflammatory potential than vitrectomy alone, and the higher rate of OCT evidence of macular edema in the study by Kim et al may have been secondary to the preoperative macular disease profile and prospective nature of the research. In the current series, $64 \%$ of eyes had preoperative macular edema from a variety of macular pathologies. Inevitably, more preoperative macular edema will predispose towards a high rate of postoperative macular edema. Eyes in the current series were thus divided into those with macular edema preoperatively and those without. Those eyes with preoperative macular edema had a mean decrease in central subfield thickness of $46.9 \mu \mathrm{m}$ which was statistically significant. Twenty five percent of those eyes had no evidence of macular edema on postoperative OCT. The eyes without pre-existing macular edema, on the other hand, had a statistically insignificant mean increase of $10.6 \mu \mathrm{m}$. This is not surprising, because these retinas would not be expected to get much thinner in the absence of preoperative macular edema. Two of these eyes (6.3\%) developed macular edema by the study definition.

The primary pathology that prompted the vitrectomy portion of the procedure in the current study was 
particularly varied. This was a consequence of the practice setting; the primary surgeon is a tertiary referral ocular oncologist who has a large population of patients with tumors and post-radiation. Both of these conditions can be markedly proinflammatory, and one would expect a greater tendency towards postoperative macular edema in this group than in otherwise healthy patients with more typical macular pathology like epiretinal membranes or macular holes. The relatively low rate of postoperative macular edema, as well as the statistically significant reduction in mean central subfield in those eyes with preoperative macular edema, can be attributed to the adjunctive intravitreal triamcinolone acetonide. Intravitreal triamcinolone acetonide modulated the inflammatory potential of both the surgery and the underlying disease.

The underlying pathology is also likely the reason for the relatively limited improvement in visual acuity in this study. A number of patients had radiation optic neuropathy and longstanding macular edema, which would limit visual potential regardless of improvement in macular edema. Both the eyes with preoperative macular edema and those without showed a trend towards improved best-corrected visual acuity after surgery that did not reach statistical significance. Multiple factors, including cataract removal and other therapeutic aspects of the vitrectomy, probably contributed to the improvement in vision.

Secondary ocular hypertension is the primary concern with intravitreal triamcinolone acetonide in this setting. However, while the risk of glaucoma with intravitreal triamcinolone acetonide alone has been well described, the intraocular pressure effect of intravitreal triamcinolone acetonide in the setting of vitrectomy is not as well known. ${ }^{24-26}$ The SCORE (Standard Care vs Corticosteroid for Retinal Vein Occlusion) study, for instance, excluded patients with prior vitrectomy from its ocular hypertension analysis. ${ }^{27}$ Vitrectomized animal eyes display different pharmacokinetics than nonvitrectomized eyes, and intravitreal triamcinolone acetonide clears faster in vitrectomized eyes. ${ }^{28,29}$ Two recent clinical studies have reported relatively low rates of secondary ocular hypertension with intravitreal triamcinolone acetonide when it is injected immediately after vitrectomy. ${ }^{11,14}$ Mean intraocular pressure in the current series trended down after the procedure, and $7 \%$ of eyes registered a pressure value over $25 \mathrm{mmHg}$. No eyes required surgical intervention for secondary open-angle glaucoma.

The current study is limited by its retrospective data source, lack of control arm, and single-surgeon experience. The extent to which vitrectomy and surgical technique affects postoperative inflammation and macular edema is unclear. Vitrectomy enhances oxygen delivery to the inner retina as well as the posterior lens surface. Increased oxygen surface tension may prompt arteriolar vasoconstriction as well as downregulation of production of vascular endothelial growth factor by ischemic tissue, both of which diminish macular edema. ${ }^{30,31}$ Thus, vitrectomy in itself changes the microenvironment and alters macular edema to a degree. A large number of eyes that underwent combined phacoemulsification with vitrectomy and intravitreal triamcinolone acetonide were excluded due to lack of available OCT or to gross macular pathology that distorted the foveal anatomy and rendered evaluation of macular edema impossible, and this has potential for selection bias. Time domain OCT images were used exclusively in order to maintain consistency between examinations and across patients. The diversity of vitreoretinal pathology was again atypical and indicative of an ocular oncology referral practice. There was extensive pathology in many of these eyes, that may have played an unpredictable role.

The data from the current study suggest that in eyes with macular edema undergoing combined phacoemulsification and vitrectomy, intravitreal triamcinolone acetonide may play an important role in modulating inflammation. It may contribute to a decrease in retinal thickness and, in some eyes, rapid resolution of macular edema. The low rate of postoperative macular edema $(6.3 \%)$ when there was no edema preoperatively is slightly lower than previously published rates, and the extent to which this is attributable to intravitreal triamcinolone acetonide deserves further study. Significant secondary ocular hypertension due to intravitreal triamcinolone acetonide was not seen in this series. Combined phacoemulsification with vitrectomy and intravitreal triamcinolone acetonide was well tolerated with good visual and anatomic results in this complex patient population.

\section{Disclosure}

The authors report no conflicts of interest in this work.

\section{References}

1. Staudt S, Miller DW, Unnebrink K, et al. Incidence and extent of postoperative macular edema following vitreoretinal surgery with and without combined cataract operation. Ophthalmologe. 2003;100: 702-707. German.

2. McDonald HR, Johnson RN, Schatz H. Surgical results in the vitreomacular traction syndrome. Ophthalmology. 1994;101:1397-1402.

3. Kim SJ, Martin DF, Hubbard GB, et al. Incidence of postvitrectomy macular edema using optical coherence tomography. Ophthalmology. 2009;116:1531-1537.

4. Chaudry NA, Cohen KA, Flynn HW Jr, Murray TG. Combined pars plana vitrectomy and lens management in complex vitreoretinal disease. Semin Ophthalmol. 2003;18:132-141. 
5. Blankenship GW, Flynn HW Jr, Kokame GT. Posterior chamber intraocular lens insertion during pars plana lensectomy and vitrectomy for complications of proliferative diabetic retinopathy. Am J Ophthalmol. 1989;108:1-5.

6. Jun Z, Pavlovic S, Jacobi KW. Results of combined vitreoretinal surgery and phacoemulsification with intraocular lens implantation. Clin Exp Ophthalmol. 2001;29:307-311.

7. Wensheng L, Wu R, Wang X, et al. Clinical complications of combined phacoemulsification and vitrectomy for eyes with coexisting cataract and vitreoretinal diseases. Eur J Ophthalmol. 2009;19:37-45.

8. Lahey JM, Francis RR, Kearney JJ, et al. Combining phacoemulsification and vitrectomy in patients with proliferative diabetic retinopathy. Curr Opin Ophthalmol. 2004;15:192-196.

9. Soheilian M, Mirdehqhan SA, Peyman GA. Sutureless combined 25-gauge vitrectomy, phacoemulsification, and posterior chamber intraocular lens implantation for management of uveitic cataract associated with posterior segment disease. Retina. 2008;28:941-946.

10. Lai $\mathrm{C}$, Wang $\mathrm{N}, \mathrm{Wu} \mathrm{W}$, et al. The long-term anatomical and visual effect of intravitreal triamcinolone injection during vitrectomy for the treatment of idiopathic macular epiretinal membrane. Cutan Ocul Toxicol. 2011;30:292-297.

11. Parke III DW, Sisk RA, Houston SK, Murray TG. Ocular hypertension after intravitreal triamcinolone with vitrectomy and phacoemulsification. Clin Ophthalmol 2012;6:925-31.

12. Sisk RA, Murray TG. Combined phacoemulsification and sutureless 23-gauge pars plana vitrectomy for complex vitreoretinal disease. $\mathrm{Br}$ J Ophthalmol. 2010;94:1028-1032.

13. Ahmadabadi HF, Mohammadi M, Beheshtnejad H, et al. Effect of Intravitreal triamcinolone acetonide injection on central macular thickness in diabetic patients having phacoemulsification. J Cataract Refract Surg. 2010;36:917-922.

14. Konstantinidis L, Berguiga M, Beknazar E, et al. Anatomic and functional outcome after 23-gauge vitrectomy, peeling, and intravitreal triamcinolone for idiopathic macular epiretinal membrane. Retina. 2009;29:1119-1127.

15. Chan A, Duker JS, Ko TH, et al. Normal macular thickness measurements in healthy eyes using Stratus optical coherence tomography. Arch Ophthalmol. 2006;124:193-198.

16. Kim SJ, Belair ML, Bressler NM, et al. A method of reporting macular edema after cataract surgery using optical coherence tomography. Retina. 2008;28:870-876.

17. Enaida H, Hata Y, Ueno A, et al. Possible benefits of triamcinoloneassisted pars plana vitrectomy for retinal diseases. Retina. 2003;23: 764-770.

18. Antonetti DA, Wolpert EB, DeMaio L, et al. Hydrocortisone decreases retinal endothelial cell water and solute flux coincident with increased content and decreased phosphorylation of occludin. J Neurochem. 2002;80:667-677.
19. Kurtz RM, Elner VM, Bian ZM, et al. Dexamethasone and cyclosporine A modulation of human retinal pigment epithelial cell monocyte chemotactic protein-1 and interleukin-8. Invest Ophthalmol Vis Sci. 1997;38:436-445.

20. Bhisitkul RB, Winn BJ, Lee OT, et al. Neuroprotective effect of intravitreal triamcinolone acetonide against photoreceptor apoptosis in a rabbit model of subretinal hemorrhage. Invest Ophthalmol Vis Sci. 2008;49:4071-4077.

21. Ebrahem Q, Minamoto A, Hoppe G, Anand-Apte B, Sears JE. Triamcinolone acetonide inhibits IL-6 and VEGF-induced angiogenesis downstream of the IL-6 and VEGF receptors. Invest Ophthalmol Vis Sci. 2006;47:4935-4941.

22. Lahey JM, Francis RR, Kearney JJ, Cheung M. Combining phacoemulsification and vitrectomy in patients with proliferative diabetic retinopathy. Curr Opin Ophthalmol. 2004;15:192-196.

23. Miller JH, George JM, Hoskings JC. Combined macular hole and cataract surgery. Am J Ophthalmol. 1997;124:705-707.

24. Chuang LH, Yeung L, Wang NK, Chen HS, Ku WC, Lai CC. Secondary ocular hypertension after intravitreal injection with $2 \mathrm{mg}$ or $4 \mathrm{mg}$ of triamcinolone in retinal vein occlusion. J Ocul Pharmacol Ther. 2010;26:325-328.

25. Vasconcelos-Santos DV, Nehemy PG, Schachat AP, Nehemy MB. Secondary ocular hypertension after intravitreal injection of $4 \mathrm{mg}$ of triamcinolone acetonide. Retina. 2008;28:573-580.

26. Young S, Larkin G, Branley M, et al. Safety and efficacy of intravitreal triamcinolone for cystoid macular oedema in uveitis. Clin Exp Ophthalmol. 2001;29:2-6.

27. Ip MS, Scott IU, van Veldhuisen PC, et al; SCORE Study Research Group. A randomized trial comparing the efficacy and safety of intravitreal triamcinolone with observation to treat vision loss associated with macular edema secondary to central retinal vein occlusion: the Standard Care vs Corticosteroid for Retinal Vein Occlusion (SCORE) study report 5. Arch Ophthalmol. 2009;127:1101-1114.

28. Chin HS, Park TS, Moon YS, Oh JH. Difference in clearance of intravitreal triamcinolone acetonide between vitrectomized and nonvitrectomized eyes. Retina. 2005;25:556-560.

29. Schindler RH, Chandler D, Thresher R, Machemer R. The clearance of intravitreal triamcinolone acetonide. Am J Ophthalmol. 1982;93: 415-417.

30. Koreen L, Yoshida N, Niziol LM, et al. Incidence of, risk factors for, and combined mechanisms of late-onset open-angle glaucoma after vitrectomy. Retina. 2012;32:160-167.

31. Stefansson E. Ocular oxygenation and the treatment of diabetic retinopathy. Surv Ophthalmol. 2006;51:364-380.

\section{Dovepress}

\section{Publish your work in this journal}

Clinical Ophthalmology is an international, peer-reviewed journal covering all subspecialties within ophthalmology. Key topics include: Optometry; Visual science; Pharmacology and drug therapy in eye diseases; Basic Sciences; Primary and Secondary eye care; Patient Safety and Quality of Care Improvements. This journal is indexed on
PubMed Central and CAS, and is the official journal of The Society of Clinical Ophthalmology (SCO). The manuscript management system is completely online and includes a very quick and fair peer-review system, which is all easy to use. Visit http://www.dovepress.com/ testimonials.php to read real quotes from published authors. 